\title{
Platelet Microparticles Accelerate Proliferation and Growth of Mesenchymal Stem Cells through Longevity- Related Genes
}

\author{
Maryam Samareh Salavati Pour, PhD ${ }^{1,2,3}$; Fatemeh Hoseinpour Kasgari, MSC $^{3}$; Alireza Farsinejad, PhD ${ }^{2,3}$; Ahmad Fatemi, PhD ${ }^{3}$; \\ Gholamhossein Hassanshahi, Prof. ${ }^{4}$; Roohollah Mirzaee Khalilabadi, PhD $^{3^{*}}$ \\ ${ }^{1}$ Student Research Committee, Kerman University of Medical Sciences, Kerman, Iran \\ ${ }^{2}$ Cell Therapy and Regenerative Medicine Comprehensive Center, Kerman University of Medical Sciences, Kerman, Iran \\ ${ }^{3}$ Department of Hematology and Laboratory Sciences, Faculty of Allied Medicine, Kerman University of Medical Sciences, Kerman, \\ Iran \\ ${ }^{4}$ Department of Immunology, Medical School, Rafsanjan University of Medical Sciences and Health Services, Rafsanjan, Iran
}

\begin{abstract}
Background: Due to their self-renewal and differentiation ability, the mesenchymal stem cells (MSCs) have been studied extensively. However, the MSCs lifespan is restricted; they undergo several divisions in vitro that cause several alternations in cellular features and relatively lessens their application. Thus, this study was aimed to assess the effect of platelet-derived microparticles (PMPs), a valuable source of proteins, microRNAs (miRNAs), and growth factors, on the expression of hTERT, c-MYC, p16, p53, and p21 as the most important aging and cell longevity genes alongside with population doubling time (PDT) of PMP-treated cells in comparison to a control group.

Methods: Umbilical cord MSCs (UC-MSCs) were used in this study, whereby they reached a confluency of $30 \%$. MSCs were treated by PMPs $(50 \mu \mathrm{g} / \mathrm{mL})$, and then, PDT was determined for both groups. Quantitative expression of hTERT, c-MYC, p16, p53, and p21 was examined through quantitative real-time PCR at various intervals (i.e. after five and thirty days as well as freezingthawing process).

Results: Our results demonstrated that the treated group had a shorter PDT in comparison to the control group $(P<0.050)$. The real-Time PCR data also indicated that PMPs were able to remarkably up-regulate hTERT and c-MYC genes expression while down-regulating the expression of p16, p21, and p53 genes $(P<0.050)$, especially following five days of treatment.

Conclusion: According to these data, it appears that PMPs are a safe and effective candidate for prolonging the lifespan of UCMSCs; however, further investigations are needed to corroborate this finding.

Keywords: Aging; Blood platelets; Cell-derived microparticle; Gene expression; Mesenchymal stem cell

Cite this article as: Salavati Pour MS, Hoseinpour Kasgari F, Farsinejad A, Fatemi A, Hassanshahi G, Mirzaee Khalilabadi R. Platelet microparticles accelerate proliferation and growth of mesenchymal stem cells through longevity-related genes. Arch Iran Med. 2021;24(8):607-614. doi: 10.34172/aim.2021.86
\end{abstract}

Received: January 4, 2020, Accepted: September 30, 2020, ePublished: August 1, 2021

\section{Introduction}

Mesenchymal stem cells (MSCs), defined as nonhematopoietic, multipotential cells, possess self-renewal potential along with the ability to differentiate into mesodermal cells such as bone, cartilage, and fat. ${ }^{1-3}$ Furthermore, recent studies have provided evidence that MSCs are able to differentiate toward ectodermal and endodermal layers such as liver and neurons. ${ }^{4}$ These features make MSCs promising tools within the area of regenerative medicine and tissue engineering. ${ }^{5,6}$ Because the process of MSCs isolation to obtain sufficient number of cells from various tissue sources is difficult, their in vitro culture is almost inevitable. ${ }^{7}$ Since MSCs have a limited lifespan, they could enter the process of aging after a number of passages (approximately 6-12) in tissue culture, a phenomenon that is associated with reduced proliferation rate and differentiation potential, morphological changes as well as significantly altered expressions of genes involved in the proliferation and regulation of microRNA levels (miRNAs). ${ }^{2,4}$ Accordingly, such changes diminish the efficacy of MSCs and their research and clinical applications. Multiple parameters are able to induce aging in MSCs, including DNA damage which is caused by oxidative stress or activation of oncogenes, epigenomic disruption, telomere shortening, down-regulated expression of telomerase reverse transcriptase (hTERT) (which is regarded as a paramount factor), in addition to other both external and internal senescence-inducing stimuli. ${ }^{3,8,9}$ Expression of hTERT is normally silenced in differentiated normal cells, whereas it is increased in several types of cancers, contributing to cell immortality and carcinogenesis. ${ }^{10}$ It has been specified that the short lifespan of MSCs is entailed by loss of telomerase activity, due to low expression level of hTERT; hence, the telomere lengths of MSCs is decreased with each successive passage. ${ }^{8}$ Additionally, cellular senescence is 
also mediated by two cyclin-dependent kinase inhibitors, i.e. p53/p21CIP1 and p16INK4A/Rb, as the major cell cycle regulators, both of which are activated upon cell senescence. $^{3}$ Pluripotency genes such as OCT4 and c-MYC are responsible for maintaining the self-renewal capacity of MSCs, and are downregulated following further expansion and differentiation in vitro. ${ }^{11}$ The clinical application of MSCs is limited to the regenerative medicine and cell therapy given the dramatic changes in their characteristics arising from the aging of MSCs. ${ }^{10-12}$ Therefore, it is necessary to develop new approaches for tissue culture to overcome the aging processes of MSCs in vitro. Recent studies have introduced viral vectors for transferring genetic factors involved in proliferation such as hTERT or tumor suppressor inhibitors into the MSCs genome. ${ }^{5,13}$ The high pathogenicity, toxicity, and survival probability of the virus in living cells, in addition to expensive costs, have been identified as major drawbacks of this approach. ${ }^{2}$ Cell-derived microparticles (MPs) are plasma membrane vesicles which range from 0.05 to $1 \mu \mathrm{m}$ in size, and are released by a large number of cells such as white blood cells, platelets, red blood cells, and endothelial cells. Approximately, $70 \%-90 \%$ of MPs are shed by platelets into biological fluids, including the bloodstream. Release of MPs from cell membranes is increased in response to activation by apoptosis or other stimuli such as stress. ${ }^{14,15}$ Platelet-derived microparticles (PMPs) contain several components such as NADP, growth factors, oxidases, chemotactic factors, and other essential cellular deposits, ${ }^{14}$ mediating the shuttling of active molecules such as lipids, enzymes, and growth factors to recipient cells. Moreover, it has been assumed that these PMPs contain mRNAs and miRNAs. ${ }^{16}$ Essentially, PMPs play several roles in cell-cell interactions, including immunomodulation, inflammation, vascularization, vascular repair, and most importantly, cell survival and death. ${ }^{17-19}$ The present project aimed to evaluate the effect of PMPs as non-viral, harmless, and an efficient method for prolonging the longevity of MSCs. The present research was also designed to investigate the effects of PMPs as the carrier of growth factors and miRNAs on hTERT, c-MYC, p16, p21 and p53 as the most essential genes required for proliferation and immortalization and to evaluate the potential of PMPs in increasing the longevity of MSCs.
Materials and Methods

Isolation and Expansion of Umbilical Cord-Derived MSCs

This step of the present study was accomplished throughout the period from January to March 2019 and was approved by the ethics committee of Kerman University of Medical Sciences, Kerman, Iran with obtaining written informed consent from donors. Women undergoing cesarean deliveries at the end of gestation in the Obstetrics and Gynecology Department of Afzalipour University Hospital of Kerman were included in this study based on the inclusion/exclusion criteria. The inclusion criteria were single pregnancy, optional or secondary cesarean section and willingness to join the study. The criteria for exclusion were no reassurance from fetus heart rate pattern, placenta previa, premature birth, fetal growth restriction, and maternal hemoglobin concentration less than $10 \mathrm{~g} / \mathrm{dL}$. After inclusion and before cesarean delivery, women were randomly allocated to two groups using random selection of opaque sealed envelopes: (1) collection of cord blood before placental delivery, and (2) obtaining cord blood after placental delivery. Then, we randomly selected six umbilical cords (UCs) from them. Their information is shown in Table 1. Under sterile and aseptic conditions, UC samples (approximately 20 $\mathrm{cm}$ ) were chopped into small pieces by surgical scissors and blade. The sections were rinsed three times with equal volumes of phosphate-buffered saline (PBS; Sigma Aldrich, USA) to eliminate red blood cells. The segments were then positioned on $10 \mathrm{~cm}$ plates with $15 \mathrm{~mL}$ complete media including low-glucose Dulbecco's modified Eagle's medium (DMEM; Gibco, UK) supplemented with 10\% of fetal bovine serum (FBS; Gibco, UK), penicillin (100 $\mathrm{U} / \mathrm{mL})$, and streptomycin $(100 \mu \mathrm{g} / \mathrm{mL} ; \mathrm{Gibco}, \mathrm{UK})$ and maintained at $37^{\circ} \mathrm{C}$ with $5 \% \mathrm{CO}_{2}$ in environment with humidification. The culture medium was further replaced every three days until confluency of the cells was achieved. Following approximately two weeks and whenever the fibroblast-like cells were seen, the UC pieces were removed from the plates. The cells were harvested using $0.25 \%$ Trypsin/EDTA (Gibco, UK) and seeded in T25 flasks (SPL, Life Sciences, Korea) for further expansion. Cells at passage three that showed a homogenous MSC phenotype were used for the study.

Table 1. Patients' Clinical Characteristics

\begin{tabular}{|c|c|c|c|c|c|}
\hline Age & Date of Delivery & Placenta Previa & Gestational Diabetes & Blood Pressure Level & Weight Gain During Pregnancy \\
\hline 26 & 06/01/2019 & No & No & 110/80 mm Hg & 28 Pounds \\
\hline 33 & $11 / 01 / 2019$ & No & No & 120/80 mm Hg & 15 Pounds \\
\hline 21 & $22 / 01 / 2019$ & Yes & No & 130/80 mm Hg & 21 Pounds \\
\hline 29 & 25/01/2019 & No & No & 110/70 mm Hg & 33 Pounds \\
\hline 30 & 08/02/2019 & No & No & 120/80 mm Hg & 18 Pounds \\
\hline 23 & $15 / 02 / 2019$ & No & No & 100/70 mm Hg & 39 Pounds \\
\hline
\end{tabular}




\section{Study Groups}

After the cells were treated with $50 \mu \mathrm{g} / \mathrm{mL}$ of PMPs, we divided them into the following three groups:

- Group 1: After 5 days of treatment, RNA extraction and gene expression evaluation were performed.

- Group 2: The cells were subcultured for 1 month following treatment. Then, they were evaluated for their gene expression.

- Group 3: Following treatment, the cells were frozen and kept at $-196^{\circ} \mathrm{C}$ for 2 months. After that, they were thawed and their gene expression was analyzed.

\section{Phenotypical Evaluation of Umbilical Cord-derived MSCs}

Cellular Morphology

Morphology analysis was performed using a phasecontrast microscope (Nikon, Japan) in order to verify the presence of MSCs, which was confirmed as shown in Figure 1a. ${ }^{20}$

\section{Flow Cytometry Analysis}

At the third passage, cells were harvested for analyzing the profile markers of the MSCs. After trypsinization, PBS was used for washing the cells. A total number of $1 \times 10^{5}$ MSCs were incubated in PBS, containing $10-\mu \mathrm{L}$ of CD73-FITC, CD105-PE, and CD90-PE mesenchymal markers as well as CD34-PE and CD45-FITC hematopoietic markers (BD Bioscience, USA). In addition, the isotype control against murine cells was added to detect non-specific bindings; then, the tubes were incubated (20 minutes) at room temperature (RT). BD FACSCalibur ${ }^{\mathrm{TM}}$ (Biosciences, USA) and Flomax software were used to measure and analyze flow cytometry data, respectively. ${ }^{21,22}$

\section{PMP Preparation}

Differential centrifugation is the most frequent approach for isolation of MPs. To achieve this, expired platelet concentrate bags were obtained from Kerman Blood Transfusion Center and their entire contents were transferred to Falcon tubes under sterile conditions. The tubes were twice centrifuged for 10 minutes at $5000 \mathrm{rpm}$ to separate and remove red and white blood cells and then, the resultant supernatant was centrifuged (18000 rpm, 30 minutes) to precipitate PMPs. Pellets were dissolved in DMEM $(1 \mathrm{~mL})$ and stored at $-80^{\circ} \mathrm{C}$ for further use in the experiments. ${ }^{23}$ (a)

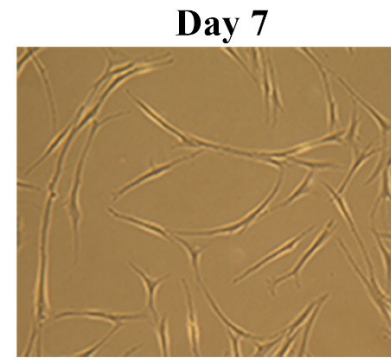

(b)

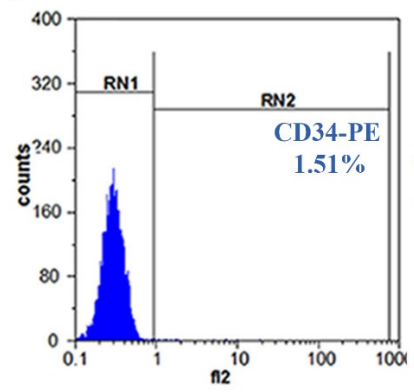

\section{Day 14}
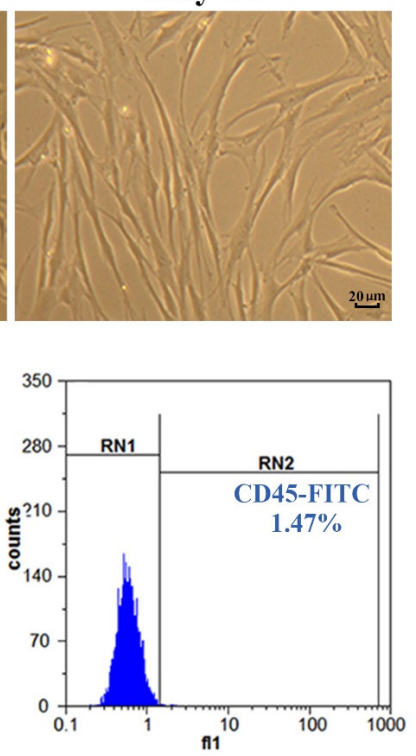
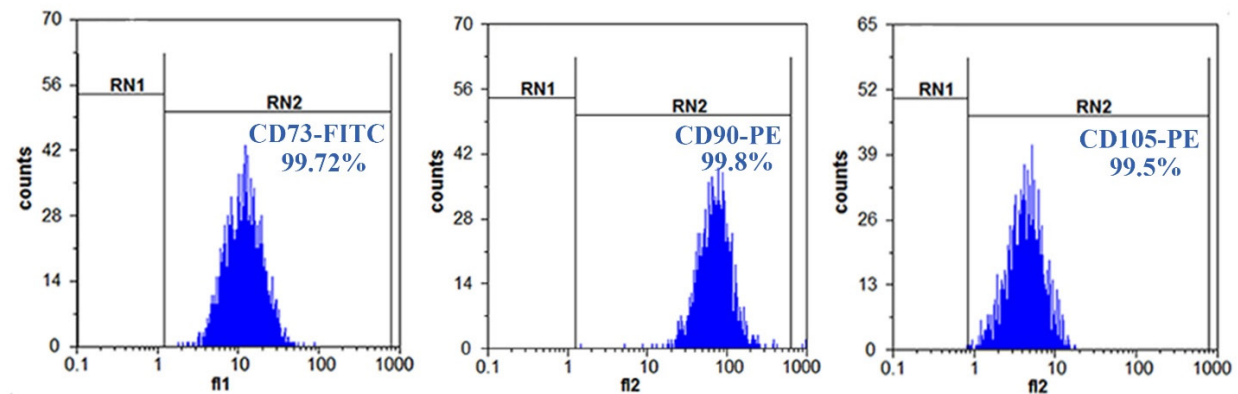

Figure 1. Characterization of UC-MSCs. (a) Fibroblast-shaped morphology of MSCs after 7 and 14 days of seeding (40X magnification). (b) Extremely low expression of CD34 and CD45 antigens and high expression levels of CD105, CD73 and CD90 antigens. RN1 and RN2 lines represent the cells with targeted markers identified by fluorescent labeled-antibodies. 


\section{Determination of PMPs Concentration Based on Bradford Assay}

The protein content of PMPs was ascertained by Bradford assay using a Nano drop spectrophotometer (Nano Photometer $^{\mathrm{Tm}}$ Pearl). Concisely, various dilutions of bovine serum albumin (BSA) were provided $(312.5,625,1250$, 2500, 5000, $10000 \mu \mathrm{g} / \mathrm{mL}$ ). Then, $200 \mu \mathrm{L}$ of Bradford solution was separately added to $10 \mu \mathrm{L}$ of BSA or MP specimens and their absorptions were assessed at $595 \mathrm{~nm}$. The standard curve was drawn against BSA samples and was used for determination of the MPs concentrations. ${ }^{23}$

\section{Characterization of PMPs}

Measurement of PMPs size was performed using a dynamic light scattering (DLS) Malvern Master Sizer 2000 laser diffraction system (Malvern Instruments Ltd, Worcestershire, UK), according to the DLS technique. In this system, a laser beam with $633 \mathrm{~nm}$ wavelength was focused into the microparticle suspension as well as DMEM media as the control sample, and the scattered light was detected. The size of microparticles and particles in the control sample was calculated by the software installed on the machine. ${ }^{24}$

Phenotypic Characterization of PMPs by Flow Cytometry To identify the cellular origin of the isolated MPs, specific platelet markers, including CD42b-PE and CD61-FITC were examined by flow cytometry analysis. For this purpose, $100 \mu \mathrm{L}$ of diluted PMP solution (1:1 ratio in PBS) was added to $10 \mu \mathrm{L}$ of each antibody alongside with isotype control. After 20 minutes incubation at room temperature and in darkness, the fluorescence activated cell sorter analysis was performed using FACSCalibur. ${ }^{23}$

\section{Calculating the Population Doubling Time}

For PDT analysis, ${ }^{25}$ a total number of $5 \times 10^{4}$ cells were cultured in $25 \mathrm{~cm}$ flasks. Following the achievement of $80 \%-90 \%$ confluency (approximately 5-7 days), and washing the cells with PBS twice, they were treated using $0.25 \%$ trypsin and pre-warmed at $37^{\circ} \mathrm{C}$. After that, complete cell culture medium was applied to stop the trypsinization process, and the cell suspension was transferred into sterile tubes. Following centrifuging the suspension at $1200 \mathrm{rpm}$ for 10 minutes, the resultant supernatant was removed and the cell pellet was washed twice with PBS. The number of cells was counted by a hemocytometer. In order to obtain the next generation of cells, $5 \times 10^{4}$ cells were subcultured in new flasks. Once the cells reached $80 \%-90 \%$ confluency, the above-mentioned steps were then repeated and the cells were counted again. Finally, PDT was calculated according to the following formula:

$$
\text { Doubling Time }=\frac{\text { duration } * \log (2)}{\log (\text { Final Concentration })-\log (\text { Initial Concentration })}
$$

Real-time PCR Amplification for Quantitative Analysis of Gene Expression

Extraction of total RNA was carried out using Trizol (Invitrogen; USA). Both the purity and integrity of the extracted RNA samples were determined using spectrophotometry and electrophoresis on agarose gel (1.5\%), respectively. Then, cDNA was synthesized from the isolated RNA samples (300 ng) in $10 \mu \mathrm{L}$ as a final volume based on the PrimeScript RT reagent (PrimeScript $1^{\text {st }}$ strand cDNA Synthesis Kit, TaKaRa, Japan) protocol. Real-time PCR reactions were performed using RotorGene $\mathrm{Q}$ in a total volume of $10 \mu \mathrm{L}$ including RealQ Plus 2x Master Mix Green (Ampliqon, Denmark), primer $(0.5 \mu \mathrm{M})$, cDNA $(70 \mathrm{ng} / \mu \mathrm{L})$, and $\mathrm{H}_{2} \mathrm{O}$. The sequences of specific primers for examined genes, including hTERT, c-MYC. p16, p53, p21, and GAPDH as internal control are presented in Table 2. All amplifications were performed in triplicate. Thermal cycles were $95^{\circ} \mathrm{C}$ for 15 minutes, 40 cycles with $95^{\circ} \mathrm{C}$ for 30 seconds and $60^{\circ} \mathrm{C}$ for 60 seconds. Gene expressions were compared across samples using $2^{-\triangle \Delta C T}$ formula.

\section{Statistical Analysis}

In order to analyze the data, the SPSS software was used (SPSS 20, IBM, USA). The normal distribution of the outcomes was analyzed using the Shapiro-Wilk test with $P>0.05$ indicating the normality of data with high confidence. In addition, the $t$ test was also performed and $P<0.05$ was considered statistically significant.

\section{Results}

Phenotypical Features of Umbilical Cord-Derived MSCs Umbilical cord-derived MSCs, which were mostly fibroblast-like in appearance, were able to adhere to culture flasks during the early days of incubation. Red blood cells were rarely seen under the light microscope after three passages, and the cells gradually generated small colonies

Table 2. Primers for Indicated Genes

\begin{tabular}{|c|c|c|}
\hline Gene & Forward Primer & Reverse Primer \\
\hline hTERT & 5'- TGACACCTCACCTCACCCAC-3' & 5'-CACTGTCTTCGACAAGTTCAC-3' \\
\hline$C-M Y C$ & 5'-GTCСTCGGATTCTCTGСTCTC-3' & 5'-CAАCATCGАTTTCTTССТСАТСТTC-3' \\
\hline p16 & 5'-CCCAACGCACCGAATAGTTA-3' & 5'-ACCAGCGTGTCCAGGAAG-3' \\
\hline p21 & 5'-CСTGTCACTGTCTTGTACСCT-3' & 5' - GCGTTTGGAGTGGTAGAAATCT-3' \\
\hline p53 & 5'-CTGGCСССТGTCATСТTCTG-3' & 5'-CCGTCATGTGCTGTGACTGC-3' \\
\hline GAPDH & 5-'GAAGGTGAAGGTCGGAGTC -3' & 5'-GAAGATGGTGATGGGATTTC-3' \\
\hline
\end{tabular}


(Figure 1a). Flow cytometric analyses indicated that over 99\% of the cells were positive for CD105 (99.5\%), CD90 (99.8\%), and CD73 (99.72\%), whereas there was no apparent expression of CD34 (1.51\%) or CD45 (1.47\%). Hence, the cells isolated from UC samples were confirmed as MSCs (Figure 1b).

\section{Characterization of PMPs by DLS}

As shown in Figure 2b, size dispersion was observed in the range of 190.1-396.1 nm for PMPs and 24.36- 68.06 for particles in DMEM medium (Figure 2a).

\section{Phenotypical Characterization of PMPs}

Immunophenotypic analysis of PMPs was ascertained by flow cytometry and showed that PMPs significantly expressed CD61 (99.64\%) and CD42b (90.93\%) (Figure 3).

\section{PDT of Umbilical Cord-Derived MSCs}

The PDT of the treated group was significantly decreased when MSCs were treated with PMPs $(50 \mu \mathrm{g} / \mathrm{mL})$ in comparison to the control group (PMPs untreated cells) (33.12 \pm 0.015 versus $48 \pm 0$ hours, $P=0.034)$.

\section{Effect of PMPs on Gene Expression}

Following treatment of cells with $50 \mu \mathrm{g} / \mathrm{mL}$ of PMPs, the profile of gene expression was evaluated following five (group 1) and thirty (group 2) days as well as after two months of freezing-thawing processes (group 3). The mean and standard deviation of the outcomes, compared to the

a)

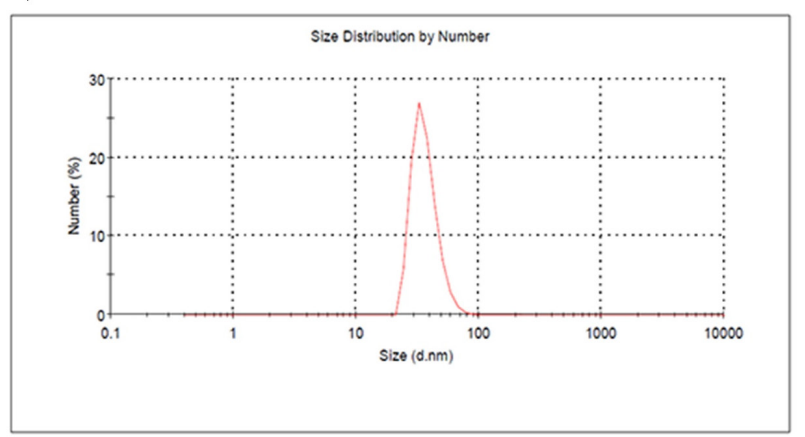

b)

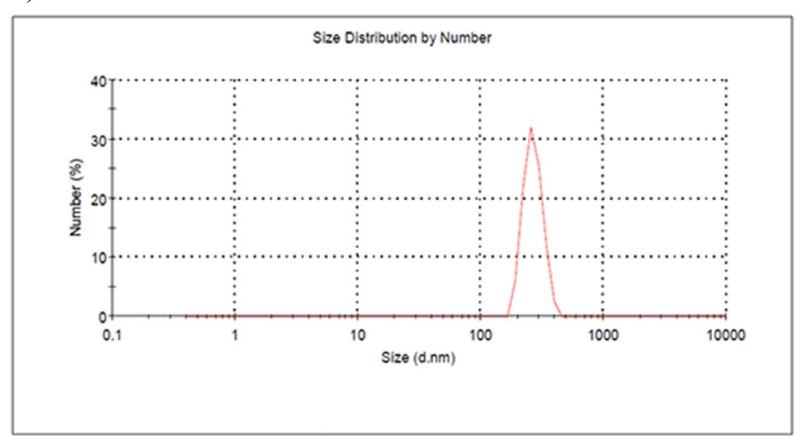

Figure 2. DLS Analysis of the Size Distribution of PMPs (a) and Particles in DMEM Medium (b).
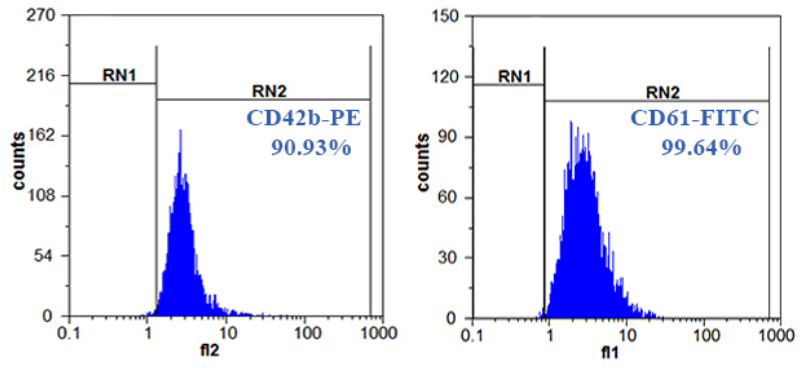

Figure 3. Phenotype of PMPs. High expression of CD61 and CD42b on the surface of PMPs.

internal control group, are provided in Table 3. As shown in Figure $4 \mathrm{a}$, the expression of hTERT gene increased significantly in group 1 (by 3.5 folds, $P=0.050$ ), group 2 (by 2.4 folds, $P=0.050$ ), and group 3 (by 1.4 folds, $P=0.011$ ) in comparison to the control group. The expression of c-MYC gene was also significantly upregulated in group 1 (by 2.8 folds, $P=0.042$ ), group 2 (by 2.1 folds, $P=0.045$ ), and group 3 (by 1.6 folds, $P=0.003$ ), compared to the control (Figure $4 \mathrm{~b}$ ). The result of p16 gene showed that its expression was significantly lower in group $1(0.18$, $P=0.003)$, group $2(0.5, P=0.014)$, and group $3(0.35$, $P=0.034)$ compared with the control (Figure $4 c$ ). We also found that the expression of $\mathrm{p} 21$ gene was significantly downregulated in group 1 ( 0.02 fold, $P=0.004)$, group 2 (0.79 fold, $P=0.024)$, and group 3 ( 0.26 fold, $P=0.026)$ in comparison to the control group (Figure $4 \mathrm{~d}$ ). Finally, the results indicated that the expression of $\mathrm{p} 53$ was remarkably downregulated in group 1 ( 0.21 fold, $P=0.0001)$, group 2 (0.63 fold, $P=0.022$ ), and group 3 (0.47 fold, $P=0.030$ ) compared to the control group (Figure 4e).

\section{Discussion}

Aging is defined as a main factor in limiting the clinical applications of MSCs in several aspects such as cell therapy and regenerative medicine, which was initially postulated by Leonard Hayflick in 1960. The aging process is inherent and complex, manifesting inside an organism at cellular and molecular levels. ${ }^{26,27}$ At the molecular level, the expression of some markers is associated with cell senescence and lifespan of MSCs. Shortened telomere length and altered TERT expression are among prominent factors, such that their fold changes have an inverse association with the proliferative capacity and lifespan of MSCs. ${ }^{10,26}$ However, evidence suggests that sheer shortening of telomere length does not call for aging of MSCs. ${ }^{5,28}$ Two main tumor suppressor pathways, namely p16INK4A/pRb and p53/ p21WAF1, are also known as permanent factors implicated in MSC senescence. Some senescent states are primarily determined by high expression of p16 while others are specified by $\mathrm{p} 53$, which is needed for coupling of arrested cell cycle progression to other cellular responses in order to face with various physiological requirements and to meet the deserved responses to different forms of stress. ${ }^{3}$ Therefore, the present study focused on the role of PMPs 
Table 3. Mean and Standard Deviation and Related 95\% Confidence Interval of Difference of the Outcomes

\begin{tabular}{|c|c|c|c|c|c|c|}
\hline & & \multirow{2}{*}{ Mean } & \multirow{2}{*}{$\begin{array}{l}\text { Standard } \\
\text { Deviation }\end{array}$} & \multicolumn{2}{|c|}{$95 \%$ Confidence Interval of Difference } & \multirow{2}{*}{ Sig (2-Tailed) } \\
\hline & & & & Lower & Upper & \\
\hline \multirow{3}{*}{ hTERT } & Group 1 & -2.61527 & 0.28953 & -5.21661 & -0.01393 & 0.050 \\
\hline & Group 2 & -0.43500 & 0.04950 & -0.87972 & 0.00972 & 0.050 \\
\hline & Group 3 & -1.41500 & 0.03536 & -1.73266 & -1.09734 & 0.011 \\
\hline \multirow{3}{*}{ c-MYC } & Group 1 & -1.43500 & 0.13435 & -2.64209 & -0.22791 & 0.042 \\
\hline & Group 2 & -0.49500 & 0.04950 & -0.93972 & -0.05028 & 0.045 \\
\hline & Group 3 & -1.11500 & 0.00707 & -1.17853 & -1.05147 & 0.003 \\
\hline \multirow{3}{*}{ P16 } & Group 1 & 0.94500 & 0.00707 & 0.88147 & 1.00853 & 0.003 \\
\hline & Group 2 & 0.69500 & 0.02121 & 0.50441 & 0.88559 & 0.014 \\
\hline & Group 3 & 0.56000 & 0.04243 & 0.17881 & 0.94119 & 0.034 \\
\hline \multirow{3}{*}{ P53 } & Group 1 & 0.79500 & 0.00707 & 0.73147 & 0.85853 & 0.004 \\
\hline & Group 2 & 0.53000 & 0.02828 & 0.27588 & 0.78412 & 0.024 \\
\hline & Group 3 & 0.36500 & 0.02121 & 0.17441 & 0.55559 & 0.026 \\
\hline \multirow{3}{*}{ P21 } & Group 1 & -0.96500 & 0.02121 & -1.15559 & -0.77441 & 0.0001 \\
\hline & Group 2 & 0.72500 & 0.03536 & 0.40734 & 1.04266 & 0.022 \\
\hline & Group 3 & 0.21000 & 0.01000 & 0.08294 & 0.33706 & 0.030 \\
\hline
\end{tabular}

Note. The comparisons are made with the internal control group.

in the expression of these genes as outstanding markers of aging. PMPs have been identified to carry growth factors, proteins, miRNA, enzymes, and lipids, in addition to the other biologically active compounds and have become a focus of several studies. ${ }^{29,30}$ Baj-Krzyworzeka et al indicated that PMPs induce the release of cytokines and expression of growth factors, alongside the inhibition of apoptosis in hematopoietic cells. ${ }^{31}$ Furthermore, Dashevsky et al reported that PMPs are able to mediate the proliferation and survival of prostate cancer cells in vitro. ${ }^{32}$ According to these observations, we hypothesized that PMPs possess the potential to improve the lifespan of MSCs during in vitro culture. Our results demonstrated that the treatment of MSCs with $50 \mu \mathrm{g} / \mathrm{mL}$ of PMPs significantly increased hTERT and c-MYC gene expressions. Bocker et al and Huang et al conducted experiments aimed at increasing the lifespan of MSCs. They exogenously delivered hTERT into MSCs using viral vectors and improved the lifespan of MSCs. ${ }^{13,33}$ Additionally, Farahzadi et al investigated the effect of L-carnitine (an antioxidant
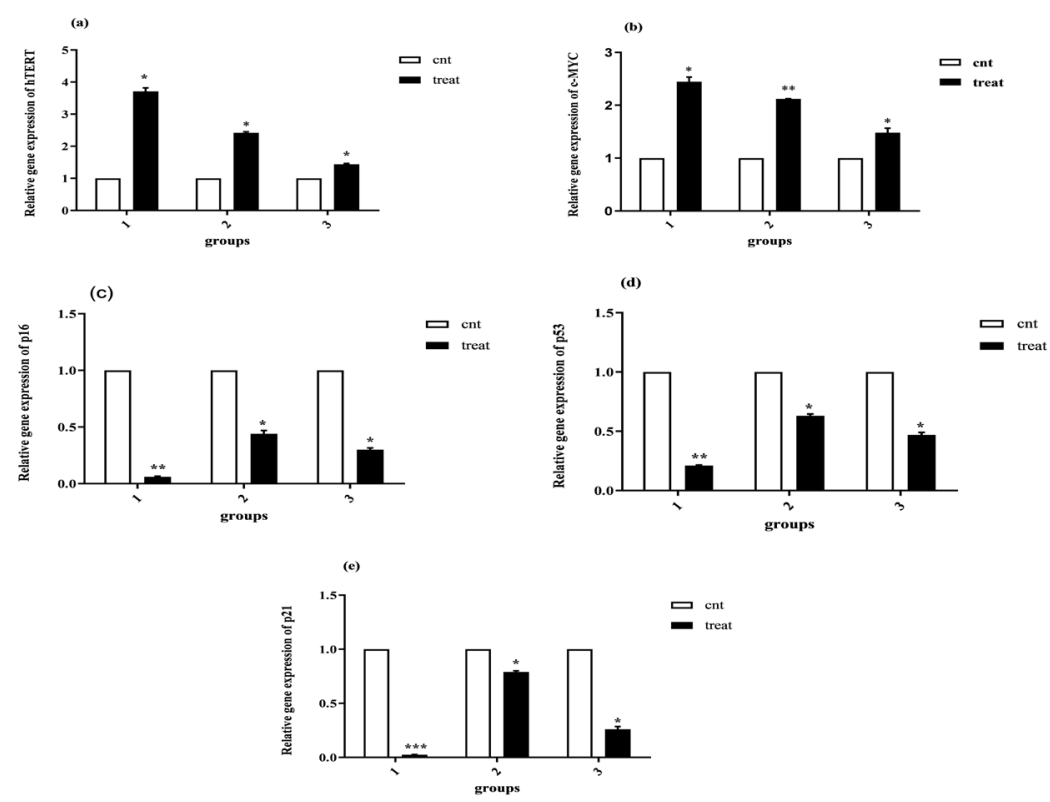

Figure 4. Analysis of Gene Expressions. As described in related sections, the result of real-time PCR showed that PMPs significantly enhanced hTERT and c-MYC gene expression and reduced the expression of p53, p21 and p16 genes. All values are presented as mean \pm SD and normalized by GAPDH $(n=3, * P<0.050 ; * * P<0.010 ; * * * P<0.001)$ 
potentially serving as a non-viral method) on gene expression of TERT as well as telomere length and showed that L-carnitine effectively increased the expression of hTERT in adipose tissue-derived MSCs. ${ }^{10}$ Likewise, we showed that PMPs decreased p16, p53, and p21 gene expression compared with untreated cells of the control group. As reported by Okamato et al, both telomerase activity and inactivation of $\mathrm{Rb} / \mathrm{p} 16 \mathrm{INK} 4 \mathrm{~A}$ are highly required for immortalization of MSCs. ${ }^{34} \mathrm{Gu}$ et al showed that the upregulation of p16INK4A is a key marker for promoting senescence in bone marrow-derived MSCs (BM-MSCs). ${ }^{35}$ Nevertheless, Campisi stated that p53 and p16INK4a induce senescence in non-embryonic tissues and that p21 stimulates senescence in embryonic tissues. ${ }^{36}$ Additionally, Piccinato et al reported that the expression of p21WAF1 was reduced in senescent BM-MSCs. These studies are not consistent with our results regarding the p21 gene. ${ }^{3}$ On the other hand, we investigated the effect of PMPs after different periods (after five and thirty days as well as during the freezing-thawing process) in order to evaluate the time-dependent effects. Maximum effect was observed after five days and it was inversely reduced over time (after thirty days). The effect of PMPs was also maintained at an appropriate level during the freezingthawing process. Besides, following shorter PDT in PMPtreated cells in comparison with the control group, we demonstrated that PMP was able to increase the growth rate of MSCs, a property that can be attributed to the presence of various miRNA or signaling pathways. In this regard, Baj-Krzyworzeka et al in 2002 showed that PMPs could activate two principal signaling pathways involved in cell survival and proliferation, i.e. MAPKp42/44 and PI3K-AKT. ${ }^{31}$ Moreover, studies have indicated that PMPs can transfer some miRNAs involved in proliferation and metastasis (e.g. MiR-223 and miR-939) into cells. ${ }^{37,38}$ Additionally, using expired platelet concentrate bags in this study provided high concentrations of PMPs and presented a cost-effective method. However, other factors like DNA damage, oxidative stress, and epigenetic changes could induce the aging process in MSCs, which were not assessed in the present study. ${ }^{3,4}$ Hence, more studies are highly needed to determine the whole scope of the effect of MSCs treatment with PMP in vitro.

\section{Authors' Contribution}

RMK: supervised all aspects of the work, designing the original concept of the manuscript. MS: data collection, immunoprofiling interpretation. $\mathrm{MS}$ and $\mathrm{FH}$ : performing real-time PCR experiments and interpretation of the results. AF, GH and AF: providing critical reviews and revisions in order to promote the manuscript. All authors equally contributed to writing and editing the manuscript.

\section{Conflict of Interest Disclosures}

All the authors of the manuscript declare that they have no conflicts of interest.

\section{Ethical Statement}

Collecting informed consent and conducting all the experimental processes were on the basis of the Ethical Committee of Kerman University of Medical Sciences' guidelines, Kerman, Iran; No: 95000420 .

\section{Acknowledgments}

We are thankful to the Faculty of Paramedical and Neuroscience Research Center of Kerman University of Medical Sciences, as well as the Blood Transfusion Center of Kerman Province for their invaluable scientific and financial support.

\section{References}

1. Zhao K, Liu Q. The clinical application of mesenchymal stromal cells in hematopoietic stem cell transplantation. J Hematol Oncol. 2016;9(1):46. doi: 10.1186/s13045-0160276-z.

2. Liu TM, Ng WM, Tan HS, Vinitha D, Yang Z, Fan JB, et al. Molecular basis of immortalization of human mesenchymal stem cells by combination of p53 knockdown and human telomerase reverse transcriptase overexpression. Stem Cells Dev. 2013;22(2):268-78. doi: 10.1089/scd.2012.0222.

3. Piccinato CA, Sertie AL, Torres N, Ferretti M, Antonioli E. High OCT4 and low p16(INK4A) expressions determine in vitro lifespan of mesenchymal stem cells. Stem Cells Int. 2015;2015:369828. doi: 10.1155/2015/369828.

4. Samareh Salavati Pour M, Vahidi R, Lashkari M, Derakhshani A, Ameri Z, Farsinejad A. Cord blood serum harvesting by hydroxyethyl starch: a fetal bovine serum alternative in expansion of umbilical cord-derived mesenchymal stem cells. Cytotechnology. 2020;72(4):55167. doi: 10.1007/s10616-020-00404-9.

5. Pouryazdanpanah N, Dabiri S, Derakhshani A, Vahidi R, Farsinejad A. Peripheral blood-derived mesenchymal stem cells: growth factor-free isolation, molecular characterization and differentiation. Iran $\mathrm{J}$ Pathol. 2018;13(4):461-6.

6. Bonab MM, Alimoghaddam K, Talebian F, Ghaffari SH, Ghavamzadeh A, Nikbin B. Aging of mesenchymal stem cell in vitro. BMC Cell Biol. 2006;7:14. doi: 10.1186/14712121-7-14.

7. Bourgine P, Le Magnen C, Pigeot S, Geurts J, Scherberich A, Martin I. Combination of immortalization and inducible death strategies to generate a human mesenchymal stromal cell line with controlled survival. Stem Cell Res. 2014;12(2):584-98. doi: 10.1016/j.scr.2013.12.006.

8. Franzen J, Wagner W, Fernandez-Rebollo E. Epigenetic modifications upon senescence of mesenchymal stem cells. Curr Stem Cell Rep. 2016;2(3):248-54. doi: 10.1007/s40778016-0051-7.

9. Abdallah BM, Haack-Sørensen M, Burns JS, Elsnab B, Jakob F, Hokland P, et al. Maintenance of differentiation potential of human bone marrow mesenchymal stem cells immortalized by human telomerase reverse transcriptase gene despite [corrected] extensive proliferation. Biochem Biophys Res Commun. 2005;326(3):527-38. doi: 10.1016/j. bbrc.2004.11.059.

10. Farahzadi R, Mesbah-Namin SA, Zarghami N, Fathi E. L-carnitine effectively induces hTERT gene expression of human adipose tissue-derived mesenchymal stem cells obtained from the aged subjects. Int J Stem Cells. 2016;9(1):107-14. doi: 10.15283/ijsc.2016.9.1.107. 
11. Mas-Bargues C, Viña-Almunia J, Inglés M, Sanz-Ros J, Gambini J, Ibáñez-Cabellos JS, et al. Role of p16(INK4a) and BMI-1 in oxidative stress-induced premature senescence in human dental pulp stem cells. Redox Biol. 2017;12:690-8. doi: 10.1016/j.redox.2017.04.002.

12. Li Y, Wu Q, Wang Y, Li L, Bu H, Bao J. Senescence of mesenchymal stem cells (Review). Int J Mol Med. 2017;39(4):775-82. doi: 10.3892/ijmm.2017.2912.

13. Böcker W, Yin Z, Drosse I, Haasters F, Rossmann O, Wierer $\mathrm{M}$, et al. Introducing a single-cell-derived human mesenchymal stem cell line expressing hTERT after lentiviral gene transfer. J Cell Mol Med. 2008;12(4):134759. doi: 10.1111/j.1582-4934.2008.00299.x.

14. Wang ZT, Wang Z, Hu YW. Possible roles of plateletderived microparticles in atherosclerosis. Atherosclerosis. 2016;248:10-6. doi: 10.1016/j.atherosclerosis.2016.03.004.

15. Tushuizen ME, Diamant M, Sturk A, Nieuwland R. Cellderived microparticles in the pathogenesis of cardiovascular disease: friend or foe? Arterioscler Thromb Vasc Biol. 2011;31(1):4-9. doi: 10.1161/atvbaha.109.200998.

16. Siljander PR. Platelet-derived microparticles - an updated perspective. Thromb Res. 2011;127 Suppl 2:S30-3. doi: 10.1016/s0049-3848(10)70152-3.

17. Nomura S. Function and clinical significance of plateletderived microparticles. Int J Hematol. 2001;74(4):397-404. doi: 10.1007/bf02982082.

18. Kriebardis AG, Antonelou MH, Georgatzakou HT, Tzounakas VL, Stamoulis KE, Papassideri IS. Microparticles variability in fresh frozen plasma: preparation protocol and storage time effects. Blood Transfus. 2016;14(2):228-37. doi: 10.2450/2016.0179-15.

19. Esmaili MA, Yari F, Sharifi Z, Nikougoftar M, Fadaei R. Effects of platelet microparticles on the activation of B cells. Pathobiol Res. 2013;15(4):1-10. [Persian].

20. Franke J, Abs V, Zizzadoro C, Abraham G. Comparative study of the effects of fetal bovine serum versus horse serum on growth and differentiation of primary equine bronchial fibroblasts. BMC Vet Res. 2014;10:119. doi: 10.1186/17466148-10-119.

21. Pouryazdanpanah N, Vahidi R, Dabiri S, Derakhshani A, Farsinezhad A. Use of some additives for improving mesenchymal stem cell isolation outcomes in non-mobilized peripheral blood. Arch Iran Med. 2018;21(8):362-7.

22. Vahidi R, Safi S, Farsinejad A, Panahi N. Citrate and celecoxib induce apoptosis and decrease necrosis in synergistic manner in canine mammary tumor cells. Cell Mol Biol (Noisy-le-grand). 2015;61(5):22-8.

23. Manoochehrabadi T, Sharifi Z, Yari F. Role of plateletderived microparticles in transfer of the chemokine receptor CXCR4 to CXCR4-negative cells. Med J Islam Repub Iran. 2019;33:55. doi: 10.34171/mjiri.33.55.

24. Labrie A, Marshall A, Bedi H, Maurer-Spurej E. Characterization of platelet concentrates using dynamic light scattering. Transfus Med Hemother. 2013;40(2):93100. doi: 10.1159/000350362.

25. Tsai AI, Hong HH, Lin WR, Fu JF, Chang CC, Wang IK, et al. Isolation of mesenchymal stem cells from human deciduous teeth pulp. Biomed Res Int. 2017;2017:2851906. doi: 10.1155/2017/2851906.

26. Farahzadi R, Fathi E, Mesbah-Namin SA, Zarghami N. Zinc sulfate contributes to promote telomere length extension via increasing telomerase gene expression, telomerase activity and change in the TERT gene promoter CpG island methylation status of human adipose-derived mesenchymal stem cells. PLoS One. 2017;12(11):e0188052. doi: 10.1371/ journal.pone.0188052.

27. Turinetto V, Vitale E, Giachino C. Senescence in human mesenchymal stem cells: functional changes and implications in stem cell-based therapy. Int J Mol Sci. 2016;17(7). doi: 10.3390/ijms17071164.

28. Samareh Salavati Pour M, Hoseinpoor Kasgari F, Farsinejad A, Fatemi A, Mirzaee Khalilabadi R. Platelet-derived microparticles increase the expression of hTERT gene in umbilical cord mesenchymal stem cells. Res Mol Med. 2017;5(4):31-40. doi: 10.18502/rmm.v5i4.3063.

29. Mathivanan S, Ji H, Simpson RJ. Exosomes: extracellular organelles important in intercellular communication. J Proteomics. 2010;73(10):1907-20. doi: 10.1016/j. jprot.2010.06.006.

30. Żmigrodzka M, Guzera M, Miśkiewicz A, Jagielski D, Winnicka A. The biology of extracellular vesicles with focus on platelet microparticles and their role in cancer development and progression. Tumour Biol. 2016;37(11):14391-401. doi: 10.1007/s13277-016-5358-6.

31. Baj-Krzyworzeka M, Majka M, Pratico D, Ratajczak J, Vilaire G, Kijowski J, et al. Platelet-derived microparticles stimulate proliferation, survival, adhesion, and chemotaxis of hematopoietic cells. Exp Hematol. 2002;30(5):450-9. doi: 10.1016/s0301-472x(02)00791-9.

32. Dashevsky O, Varon D, Brill A. Platelet-derived microparticles promote invasiveness of prostate cancer cells via upregulation of MMP-2 production. Int J Cancer. 2009;124(8):1773-7. doi: 10.1002/ijc.24016.

33. Huang G, Zheng Q, Sun J, Guo C, Yang J, Chen R, et al. Stabilization of cellular properties and differentiation mutilpotential of human mesenchymal stem cells transduced with hTERT gene in a long-term culture. J Cell Biochem. 2008;103(4):1256-69. doi: 10.1002/jcb.21502.

34. Okamoto T, Aoyama T, Nakayama T, Nakamata T, Hosaka T, Nishijo K, et al. Clonal heterogeneity in differentiation potential of immortalized human mesenchymal stem cells. Biochem Biophys Res Commun. 2002; 295(2): 354-61. doi: 10.1016/s0006-291x(02)00661-7.

35. Gu Z, Cao X, Jiang J, Li L, Da Z, Liu H, et al. Upregulation of p16INK4A promotes cellular senescence of bone marrowderived mesenchymal stem cells from systemic lupus erythematosus patients. Cell Signal. 2012;24(12):2307-14. doi: 10.1016/j.cellsig.2012.07.012.

36. Campisi J. Cell biology: the beginning of the end. Nature. 2014;505(7481):35-6. doi: 10.1038/nature12844.

37. Lazar S, Goldfinger LE. Platelet microparticles and miRNA transfer in cancer progression: many targets, modes of action, and effects across cancer stages. Front Cardiovasc Med. 2018;5:13. doi: 10.3389/fcrm.2018.00013.

38. Tang M, Jiang L, Lin $\mathrm{Y}, \mathrm{Wu} \mathrm{X}$, Wang K, He Q, et al. Platelet microparticle-mediated transfer of miR-939 to epithelial ovarian cancer cells promotes epithelial to mesenchymal transition. Oncotarget. 2017;8(57):97464-75. doi: 10.18632/ oncotarget.22136. 